\title{
ANALISIS FAKTOR-FAKTOR YANG MEMENGARUHI FINANCIAL SATISFACTION PENGGUNA E-WALLET
}

\author{
May Amelia \\ Universitas Negeri Surabaya \\ may.17080574101@mhs.unesa.ac.id \\ Yuyun Isbanah \\ Universitas Negeri Surabaya \\ yuyunisbanah@unesa.ac.id
}

\begin{abstract}
The research aims to determine the effect of financial literacy, financial strain, financial management behaviour, and income on financial satisfaction in the e-wallet user in Surabaya. The research is a type of conclusive causality research with quantitative research data using purposive sampling and snowball sampling techniques. The data collection instrument used in this research was the distribution of online questionnaires. The samples used in this research were 207 respondents from e-wallet user in Surabaya. The data analysis use Structural Equation Model (SEM) technique with AMOS tools. This research shows that only financial management behaviour influences financial satisfaction because of their good financial management awareness. Financial literacy has no financial satisfaction because the information is easy to get, but what is received is not necessarily correct. Financial strain has no influences on financial satisfaction because respondent did not experience financial strain, so most of them are college students and students. Income also has no influences on financial satisfaction because the income received still depends on each parent.
\end{abstract}

Keywords: financial literacy; financial management behavior; financial satisfaction; financial strain; income.

\section{PENDAHULUAN}

Uang elektronik merupakan salah satu pemanfaatan teknologi dibidang elektronik. Adanya uang elektronik memudahkan seseorang dalam melakukan transaksi pembayaran secara cepat dan praktis (Bagus, 2018). Perkembangan uang elektronik di Indonesia cukup pesat, hal ini didukung dengan adanya program dari Bank Indonesia yaitu Gerakan Nasional Non Tunai yang dilakukan sejak tahun 2014 yang bertujuan untuk memberikan pengetahuan kepada masyarakat mengenai instrumen keuangan non tunai (Zuhra, 2016). Bank Indonesia juga telah menerbitkan peraturan khusus mengenai uang elektronik yaitu Peraturan Bank Indonesia Nomor 20/6/PBI/2018 dan telah disesuaikan dengan perkembangan uang elektronik.

Pandemi Covid-19 memberikan dampak yang serius bagi perekonomian Indonesia, termasuk juga pada volume transaksi uang elektronik. Data Bank Indonesia menunjukkan volume transaksi uang elektronik pada tahun 2020 mengalami penurunan sebesar $11 \%$, yaitu volume transaksi pada tahun 2019 sebesar 5,9 miliar, namun pada tahun 2020 hanya mencapai 4,6 miliar. Disisi lain adanya pandemi Covid-19 justru menaikkan nilai transaksi uang elektronik pada tahun 2020 yaitu sebesar 41\%, dengan nilai transaksi pada tahun 2019 sebesar 145 triliun dan pada tahun 2020 mencapai 204,9 triliun. Selain itu jumlah uang elektronik yang beredar pada tahun 2020 juga mengalami kenaikan yang cukup tinggi yaitu sebesar 48\% dari tahun 2019 (Bi.go.id, 2020).

Berdasarkan riset yang dilakukan oleh Katadata Insight Center mengenai frekuensi penggunaan $e$ wallet dan e-money, hasilnya menunjukkan bahwa dalam setiap hari masyarakat lebih banyak menggunakan $e$-wallet dibandingkan dengan e-money dengan prosentase $11,1 \%$ untuk $e$-wallet dan $9,1 \%$ untuk e-money (Pusparisa, 2020). Ipsos juga melakukan riset mengenai layanan $e$-wallet di Indonesia dan mengemukakan bahwa ShopeePay memberikan kepuasan tertinggi kepada konsumen sebesar $82 \%$, selanjutnya OVO dengan tingkat kepuasan 77\%, Gopay $71 \%$, Dana 69\%, dan Link Aja 67\% (Agung, 2020). Pemerintah menunjukkan dukungannya terhadap perkembangan e-wallet di Indonesia dengan melibatkan OVO, Link Aja, Gopay, dan Dana dalam penyaluran dana program kerja pemerintah kartu prakerja (Fauzia, 2020). 
Survey yang dilakukan oleh Moka pada tahun 2019 mengungkapkan Jawa Timur sebagai pengguna uang elektronik terbesar ketiga di Indonesia dengan angka 7,45\% dan Surabaya menjadi kota terbesar kedua dalam penggunaan mobile payment di Jawa Timur (Meilisa, 2019). Sebagai pengguna terbesar mobile payment, Kota Surabaya juga memiliki pengeluaran per kapita yang cukup tinggi hingga menempati urutan pertama pengeluaran per kapita tertinggi di Jawa Timur. Dapat diketahui bahwa masyarakat telah puas dengan uang elektronik, namun dari sisi pengelolaan keuangannya masih rendah karena dilihat dari tingkat pengeluaran yang tinggi sehingga tingkat kepuasan akan keuangannya juga rendah.

Financial satisfaction merupakan kondisi seseorang yang merasa puas dengan keadaan keuangan yang dimiliki, dimana seseorang tersebut mampu memenuhi kebutuhannya dengan uang yang dimiliki (Hasibuan et al., 2018). Seseorang dapat merasakan kepuasan keuangan apabila mampu mencapai tujuan keuangannya (Mukhafi, 2020). Terdapat beberapa faktor yang memengaruhi tingkat kepuasan keuangan seseorang. Menurut Nugraha et al. (2020) financial literacy dan income dapat memengaruhi financial satisfaction seseorang. Ali et al. (2020) mengungkapkan bahwa financial management behavior dan financial strain juga dapat memengaruhi financial satisfaction.

Financial literacy merupakan kemampuan seseorang dalam membuat keputusan keuangan yang tepat sehingga dapat meminimalisir sebuah kesalahan (Prabowo \& Asandimitra, 2021). YAP et al. (2016) mengungkapkan bahwa dengan financial literacy seseorang akan mempunyai pengetahuan yang dapat membantu dalam mengambil tindakan keuangan. Menurut Nugraha et al. (2020), financial literacy berpengaruh positif terhadap financial satisfaction, hal ini juga sejalan dengan hasil penelitian yang dilakukan oleh Candra \& Memarista (2015) dan Yulinar et al. (2020). Namun penelitian lain yang dilakukan oleh Mukhafi (2020) dan Rusdini (2021) menunjukkan hasil yang berbeda, financial literacy tidak memiliki pengaruh terhadap financial satisfaction.

Financial strain merupakan kondisi seseorang yang merasa tertekan dengan kondisi keuangannya sehingga membutuhkan dana dalam penyelesaiannya (Halim \& Astuti, 2015). Financial strain dapat dikaitkan dengan pengelolaan keuangan dan arus kas keuangan seseorang (Falahati et al., 2012). Ketika seseorang mampu mengelola keuangannya dengan baik maka permasalahan keuangannya dapat terselesaikan sehingga terhindar dari financial strain dan dapat mencapai kepuasan keuangan. Hal tersebut sejalan dengan penelitian Ali et al. (2020) dan Woodyard \& Robb (2016). Namun menurut Sherlyani \& Pamungkas (2020), financial strain tidak memengaruhi tingkat financial satisfaction seseorang.

Financial management behavior berhubungan dengan tanggung jawab seseorang dalam mengelola keuangan yang dimiliki (Mukhafi, 2020). Financial management behavior merupakan keterampilan yang dimiliki seseorang dalam merencanakan, menganggarkan, memeriksa, mengelola, mengendalikan, mencari, dan menyimpan uang yang dimilikinya untuk kehidupan sehari hari (Kholilah \& Iramani, 2013). Arifin (2018) menyatakan bahwa financial management behavior berpengaruh terhadap financial satisfaction, seseorang yang dapat mengelola keuangannya dengan baik akan menimbulkan rasa puas terhadap keuangannya. Namun hasil temuan Sherlyani \& Pamungkas (2020), menunjukkan financial management behavior tidak memiliki pengaruh terhadap financial satisfaction.

Income merupakan pendapatan yang diterima oleh seseorang pada periode waktu tertentu yang dapat digunakan untuk memenuhi kebutuhan (Candra \& Memarista, 2015). Income dapat diperoleh melalui kas dari pekerjaan, deviden, bunga tabungan, royalti, dana pensiun, maupun bonus (Wahab et al., 2019). Seseorang yang memiliki income tinggi cenderung merasa puas dengan keuangannya karena mampu memenuhi kebutuhan jangka panjang dan jangka pendek dalam hidupnya dengan kemampuan yang dimiliki (Sawitri, 2018). Hal tersebut sejalan dengan penelitian yang dilakukan oleh Sahi (2013). Namun Rusdini et al. (2020) menyatakan bahwa income tidak memiliki pengaruh terhadap financial satisfaction. 
May Amelia \& Yuyun Isbanah. Analisis Faktor-Faktor yang Memengaruhi Financial Satisfaction Pengguna $E$-Wallet

Penelitian ini bertujuan untuk mengetahui pengaruh dari financial literacy, financial strain, financial management behavior, dan income terhadap financial satisfaction pada pengguna $e$-wallet di Surabaya.

\section{KAJIAN PUSTAKA DAN PENGEMBANGAN HIPOTESIS}

\section{Theory of Planned Behavior}

Theory of planned behavior merupakan teori yang berhubungan dengan perilaku seseorang (Ajzen, 2005:118). Dalam teori ini,a seseorang akan berperilaku berdasarkan niat dan tujuan yang akan dicapai. Menurut Ajzen (2005:118) dalam berperilaku seseorang dipengaruhi oleh beberapa faktor antara lain attitude toward behavior, subjective norm, dan perceived behavioral control. Selain itu juga terdapat faktor yang memengaruhi seseorang dalam berperilaku yaitu latar belakang. Berikut latar belakang yang dikemukakan oleh Ajzen (2005:135): personal, meliputi sikap seseorang secara umum, kepribadian yang dimiliki, nilai kehidupan, emosi, dan kecerdasan; sosial, meliputi usia, jenis kelamin, suku, etnis, pendidikan, pendapatan, dan agama; informasi, meliputi pengalaman pribadi, pengetahuan, dan informasi yang di sampaikan di media. Theory of planned behavior dalam penelitian ini digunakan untuk menjelaskan variabel financial literacy, financial strain, dan financial management behavior.

\section{Subjective Well-Being}

Subjective well-being berhubungan dengan perasaan puas seseorang dan pengukuran kualitas hidup (Diener et al., 2003). Teori ini menjelaskan bahwa seseorang akan melakukan evaluasi terhadap dirinya yang meliputi reaksi emosional terhadap kejadian, suasana hati, dan penilaian terhadap perilaku yang telah dilakukan berkaitan dengan kepuasan dan pemenuhan. Hasil evaluasi yang dilakukan, digunakan dalam menentukan seberapa besar perasaan bahagia hingga kepuasan yang dialami untuk dijadikan ukuran kualitas hidup yang baik. Setiap orang mempunyai tingkat kepuasan yang berbeda beda. Tingkat kepuasan seseorang dipengaruhi oleh tingkat kesejahteraan berdasarkan afektif dan kognitif, aktivitas emosional yang terjadi, dan proses informasi emosional. Selain itu kepuasan seseorang juga memiliki hubungan yang kuat dengan kepribadian seseorang, dimana tingkat kepuasan akan bertambah seiring waktu sesuai dengan pengalaman dalam hidup seseorang (Diener $e t$ al., 2003). Teori subjective well-being dalam penelitian ini digunakan untuk menjelaskan variabel financial satisfaction dan income.

\section{Financial Satisfaction}

Financial satisfaction merupakan perasaan puas seseorang dengan kondisi keuangannya. Dengan kondisi keuangan yang baik seseorang akan merasakan kepuasan keuangan (Hasibuan et al., 2018). Menurut Nugraha et al. (2020), kepuasan keuangan menunjukkan hubungan antara kebutuhan dan kondisi keuangan seseorang. Dengan kondisi keuangan yang baik, seseorang akan mampu memenuhi kebutuhan hidupnya dengan uang yang dimiliki. Dengan terpenuhinya kebutuhan hidup seseorang maka kepuasan keuangan dapat tercapai (Joo \& Grable, 2004). Tingkat kepuasan keuangan seseorang dipengaruhi oleh pengelolaan keuangan pribadinya (Wahab et al., 2019). Dengan pengelolaan keuangan yang baik maka seseorang akan semakin mudah mencapai kepuasan keuangan (Ali et al., 2020). Hasibuan et al. (2018) menjelaskan bahwa financial satisfaction dapat diukur menggunakan beberapa indikator yaitu pendapatan, pengelolaan masalah keuangan, pemenuhan akan kebutuhan dasar, pinjaman, ketersediaan uang di masa depan, dan penentuan tujuan hidup.

\section{Financial Literacy}

Financial literacy merupakan pengetahuan yang berkaitan dengan pengelolaan terhadap uang yang dimiliki (Hasibuan et al., 2018). Adanya pengetahuan yang dimiliki akan membantu seseorang dalam membuat keputusan keuangan, dan keputusan keuangan yang baik akan mengantarkan seseorang mencapai kepuasan keuangan pribadinya. Financial literacy memberikan pemahaman keuangan seseorang yang dapat membantu dalam membuat keputusan yang tepat (YAP et al., 2016) sehingga terjadinya masalah keuangan dapat diminimalisir (Prabowo \& Asandimitra, 2021). Financial literacy dapat berpengaruh terhadap pemikiran seseorang akan keuangan pribadinya. Pemikiran dan pengelolaan yang baik terhadap keuangannya dapat membantu seseorang dalam mencapai kepuasan 
keuangan (Candra \& Memarista, 2015). Financial literacy dapat diukur dengan menggunakan empat indikator yaitu pengetahuan keuangan, simpanan dan pinjaman, asuransi, dan investasi (Chen \& Volpe, 1998).

\section{Financial Strain}

Financial strain dapat diartikan juga sebagai financial stress yang merupakan sebuah tekanan yang berpotensi membahayakan, mengancam, dan dapat menyebabkan stres pada seseorang karena kondisi ekonominya (Asebedo \& Wilmarth, 2017). Tekanan keuangan perlu dikelola dengan baik dengan melakukan pengehematan terhadap uang dan waktu (Ali et al., 2020). Dengan pengelolaan keuangan yang baik seseorang akan terhindar dari financial strain. Seseorang yang jarang mengalami tekanan keuangan akan lebih puas terhadap kondisi keuangannya (Halim \& Astuti, 2015). Financial strain dapat diukur dengan menggunakan indikator pinjaman, penghematan uang, kesadaran dalam penggunaan uang, dan penggunaan dari pendapatan yang diperoleh (Falahati et al., 2012).

\section{Financial Management Behavior}

Financial management behavior merupakan keterampilan yang dimiliki seseorang dalam merencanakan, menganggarkan, memeriksa, mengelola, mengendalikan, mencari, dan menyimpan uang yang dimilikinya untuk kehidupan sehari hari (Kholilah \& Iramani, 2013). Dengan perilaku pengelolaan keuangan yang baik, seseorang akan bertanggung jawab secara efektif terhadap penggunaan uang yang dimiliki seperti berinvestasi atau membayar pengeluaran-pengeluaran (Hasibuan et al., 2018). Seseorang dapat merasakan kesejahteraan dalam hidupnya apabila mampu mengelola keuangannya dengan baik, dengan kesejahteraan dalam hidupnya maka seseorang juga akan merasakan kepuasan keuangan (Prabowo \& Asandimitra, 2021). Financial management behavior dapat diukur menggunakan indikator yaitu mengelola pengeluaran, membayar tagihan tepat waktu, membuat rencana keuangan di masa yang akan datang, menyediakan uang, dan menyimpan uang (Dwinta, 2010).

\section{Income}

Income merupakan sesuatu yang diterima seseorang berupa hasil pendapatan, keuntungan, atau pendapatan lainnya (Sawitri, 2018). Dengan pendapatan yang dimiliki, seseorang dapat menggunakannya untuk memenuhi kebutuhan sehari hari maupun keinginannya. Semakin tinggi pendapatan yang diterima seseorang maka kebutuhannya akan terpenuhi dan kepuasan keuangannya juga akan meningkat (Candra \& Memarista, 2015). Kepuasan keuangan menunjukkan bahwa kehidupan seseorang dapat dikatakan mampu apabila aset keuangannya telah tercukupi. Dengan tingginya pendapatan yang diterima seseorang dapat meningkatkan kepuasan keuangan, sehingga perlu adanya upaya untuk meningkatkan pendapatan agar seseorang dapat merasakan kepuasan keuangan (Wahab et al., 2019). Menurut Rizkiawati \& Asandimitra (2018), besaran pendapatan seseorang dapat digolongkan menjadi pendapatan < Rp1.500.000; Rp1.500.000 hingga Rp2.500.000; Rp2.500.000 hingga Rp3.500.000; dan > Rp3.500.000.

\section{Pengaruh antar Variabel}

Pengaruh financial literacy dalam penelitian ini dijelaskan berdasarkan theory of planned behavior. Dalam berperilaku seseorang dipengaruhi oleh beberapa faktor, salah satunya adalah faktor informasi (Ajzen, 2005:135). Financial literacy dapat digolongkan dalam jenis informasi yang berupa pengetahuan, dimana informasi yang dimiliki oleh seseorang berupa pengetahuan keuangan. Sehingga dengan adanya financial literacy akan membantu seseorang dalam membuat keputusan (YAP et al., 2016) dan seseorang akan mencapai kepuasan keuangan apabila membuat keputusan secara tepat (Candra \& Memarista, 2015). Nugraha et al. (2020) menyatakan bahwa financial literacy mampu memengaruhi financial satisfaction. Hal tersebut sejalan dengan hasil penelitian Candra \& Memarista (2015); Falahati et al. (2012); Hasibuan et al. (2018); Prabowo \& Asandimitra (2021); Yulinar et al. (2020). Namun Mukhafi (2020), Rusdini, D (2021), dan YAP et al. (2016) menunjukkan hasil yang berbeda, bahwa financial literacy tidak berpengaruh terhadap financial satisfaction.

H1: Financial literacy berpengaruh terhadap financial satisfaction pengguna $e$-wallet di Surabaya. 
May Amelia \& Yuyun Isbanah. Analisis Faktor-Faktor yang Memengaruhi Financial Satisfaction Pengguna $E$-Wallet

Pengaruh financial strain terhadap financial satisfaction dalam penelitian ini didasarkan pada theory of planned behavior. Ketika seseorang tidak dapat menentukan sikap dalam mengelola keuangannya dengan baik, maka mereka akan di hadapkan dengan sebuah tekanan keuangan. Ketika seseorang mengalami financial strain maka membutuhkan dana untuk menyelesaikannya (Halim \& Astuti, 2015). Oleh karena itu seseorang harus dapat mengelola keuangannya secara bijak agar dapat terhindar dari financial strain. Halim \& Astuti (2015) juga menyatakan bahwa kepuasan keuangan berpengaruh terhadap financial satisfaction. Dimana kepuasan keuangan seseorang dapat tercapai apabila terhindar dari financial strain. Hal tersebut sejalan dengan Ali et al. (2020), Woodyard \& Robb (2016), dan Falahati et al. (2012). Namun Sherlyani \& Pamungkas (2020) mengungkapkan hasil yang berbeda pada temuannya, bahwa financial satisfaction tidak dipengaruhi oleh financial strain.

H2: Financial strain berpengaruh terhadap financial satisfaction pengguna $e$-wallet di Surabaya.

Pengaruh financial management behavior terhadap financial satisfaction dalam penelitian ini dijelaskan dengan theory of planned behavior. Tercapainya tingkat kepuasan keuangan bergantung dari perilaku seseorang dalam mengelola keuangannya (Mukhafi, 2020). Kepuasan keuangan dapat dicapai dengan mengelola keuangannya sehingga mampu memenuhi kebutuhan maupun keinginan dalam hidupnya baik jangka pendek maupun jangka panjang (Darmawan \& Pamungkas, 2019). Oleh karena itu seseorang harus mampu mengelola keuangannya secara bijak agar dapat mencapai kepuasan keuangan (Arifin, 2018). Raprayogha et al. (2020) mengungkapkan bahwa financial management behavior berpengaruh secara signifikan terhadap financial satisfaction. Hal tersebut juga didukung oleh penelitian dari Arifin (2018a), Arifin (2018b), Armilia \& Isbanah (2020), Darmawan \& Pamungkas (2019), Falahati et al. (2012), Halim \& Astuti (2015), Hasibuan et al. (2018), Mukhafi (2020), Prabowo \& Asandimitra (2021), Raprayogha et al. (2020), Saurabh \& Nandan (2018), Sawitri (2018), Wijaya \& Pamungkas (2020), Woodyard \& Robb (2016), dan YAP et al. (2016). Akan tetapi, Sherlyani \& Pamungkas (2020) mengungkapkan bahwa financial satisfaction tidak dipengaruhi oleh financial management behavior.

H3: Financial management behavior berpengaruh terhadap financial satisfaction pengguna $e$-wallet di Surabaya.

Pengaruh income terhadap financial satisfaction dalam penelitian ini dijelaskan dengan teori subjective well-being. Seseorang akan menilai kehidupannya sendiri secara subjektif yang digunakan untuk mencapai kepuasan dalam dirinya, salah satunya dalam hal keuangan. Income yang tinggi menujukkan kemampuan keuangan seseorang. Dengan income tinggi seseorang dapat memenuhi kebutuhan hidupnya dengan uang yang dimiliki sehingga dapat mencapai kepuasan keuangan (Candra \& Memarista, 2015). Income merupakan faktor yang cukup kuat dalam memengaruhi financial satisfaction seseorang (Aboagye \& Jung, 2018). Dengan income tinggi seseorang akan merasakan kepuasan keuangan. Hal tersebut didukung oleh penelitian yang dilakukan oleh Candra \& Memarista (2015), Nugraha et al. (2020), Sahi (2013), Sawitri (2018), Wahab et al. (2019). Namun Rusdini, D (2021) dan Rusdini et al. (2020) menyatakan bahwa income tidak memiliki pengaruh terhadap financial satisfaction.

H4: Income berpengaruh terhadap financial satisfaction pengguna e-wallet di Surabaya.

\section{METODE PENELITIAN}

Penelitian ini menggunakan jenis penelitian konklusif kausalitas. Jenis data yang digunakan adalah data kuatitatif yang bersumber dari data primer. Variabel dependen yang digunakan dalam penelitian yakni financial satisfaction dengan financial literacy, financial strain, financial management behavior, dan income sebagai variabel independennya. Populasi dalam penelitian ini adalah masyarakat Surabaya yang menggunakan $e$-wallet. Dalam pengambilan sampel menggunakan teknik purposive sampling dan snowball sampling, dimana teknik pengumpulan datanya melalui kuesioner yang disebar secara online. Sampel yang di pilih berdasarkan kriteria yaitu masyarakat yang berdomisili di Surabaya yang memiliki dan aktif menggunakan aplikasi e-wallet ShopeePay, Gopay, 
OVO, Dana, dan/atau Link Aja. Data yang terkumpul pada penelitian ini berjumlah 271 responden, namun sebanyak 64 responden tidak lolos kategori tempat tinggal dan 36 data tidak lolos uji outlier, sehingga hanya 171 data yang digunakan dalam penelitian ini. Jawaban responden yang berupa pernyataan diukur menggunakan skala likert, sedangkan jawaban yang berupa pertanyaan diukur menggunakan skala guttman. Skala likert akan diberikan skor 1 hingga 4, sedangkan skala guttman untuk jawaban benar akan diberikan skor 1 dan jawaban salah akan diberikan skor 0. Teknik analisis data menggunakan Structural Equation Model (SEM) dengan program AMOS versi 26.

\section{HASIL DAN PEMBAHASAN}

\section{Karakteristik Responden}

Karakteristik responden pada penelitian ini didominasi oleh perempuan sebanyak 141 dengan prosentase $68 \%$ dan laki-laki sebanyak 65 atau 31\% dengan usia rata-rata 15-24 tahun dengan prosentase $95 \%$. Responden yang menggunakan e-wallet ShopeePay berjumlah 157 responden atau $76 \%$, Gopay berjumlah 84 atau 41\%, OVO berjumlah 119 atau 57\%, Dana berjumlah 86 atau 42\%, dan Link Aja berjumlah 63 atau 30\%. Tingkat pendidikan terakhir responden terdiri dari $78 \%$ tingkat SMA, 15\% S1, 4\% Diploma, dan 2\% SMP. Status pekerjaan dari responden yaitu $81 \%$ merupakan mahasiswa, $11 \%$ bekerja, $5 \%$ pelajar, dan $4 \%$ tidak bekerja. Tingkat pengeluaran rata-rata per bulan dengan menggunakan e-wallet yaitu 75\% pengeluarannya < Rp500.000, 21\% Rp500.000 hingga Rp1.000.000, 1\% Rp1.000.000 hingga Rp1.500.000, 1\% Rp1.500.000 hingga Rp2.000.000, dan 1\% > Rp2.000.000.

\section{Uji Validitas dan Reliabilitas}

Uji validitas dilakukan dengan melihat hasil uji discriminant validity dan uji Variance Extraced (AVE). Pada uji discriminant validity dilihat dari nilai estimate standardized regression weight menunjukkan seluruh indikator berada di atas 0,5 sehingga dikatakan valid. Pada uji variance extraced seluruh variabel juga telah memenuhi syarat yaitu nilai AVE $>0,5$. Nilai AVE dari financial literacy sebesar 0,65, financial strain sebesar 0,62, financial management behavior sebesar 0,67, dan financial satisfaction sebesar 0,56.

Uji reliabilitas dilakukan dengan melihat nilai Construct Reliability (CR) dengan syarat nilai CR > 0,6 . Setelah dilakukan uji ditemukan dua variabel yang kurang reliabel yaitu financial strain dengan nilai 0,56 dan financial satisfaction dengan nilai 0,53 . Sedangkan dua variabel lainnya dikatakan reliabel dengan nilai financial literacy sebesar 0,8 dan financial management behavior sebesar 0,62.

\section{Uji Outlier dan Normalitas}

Uji outlier dilakukan dengan melihat nilai mahalanobis distance dengan syarat $\mathrm{p} 2 \geq 0,002$. Setelah dilakukan uji terdapat 36 data yang tidak lolos uji outlier sehingga harus di hapus. Data yang dioutlier adalah data responden nomor $105,156,90,171,44,200,174,134,22,179,13,195,135,94,54,117$, $36,185,180,119,187,113,114,154,137,77,104,120,164,25,58,145,63,172$, 4, dan 87. Sehingga data yang dapat dilakukan untuk uji selanjutnya hanya berjumlah 171 data responden.

Uji normalitas dilakukan dengan melihat nilai critical ratio skewness dengan syarat nilai c.r harus berada pada rentang nilai $\pm 2,580$. Setelah dilakukan uji terdapat beberapa indikator variabel yang memiliki nilai lebih dari syarat yang ditentukan sehingga dikatakan tidak terdistribusi secara normal sehingga perlu di hapus. Indikator yang di hapus yaitu X1.4, X1.5, X1.6, X1.11, X1.12, X2.1, X2.4, X3.1, X3.2, X3.5, Y1, Y3, dan Y5.

\section{Uji Kelayakan Model}

Uji kelayakan model dilakukan dengan uji goodness of fit indices dengan menggunakan kriteria GFI, AGFI, TLI, RMSEA, dan NFI. Pada pengujian pertama model dapat dikatakan belum baik karena seluruh indikator yang digunakan belum memenuhi kriteria yang ditentukan yaitu nilai GFI, AGFI, TLI, dan NFI harus > 0,900 sedangkan nilai RMSEA harus berada pada rentang nilai 0,05 hingga 0,08 . Model yang belum baik perlu dilakukan modification indices dengan menghubungkan error 
May Amelia \& Yuyun Isbanah. Analisis Faktor-Faktor yang Memengaruhi Financial Satisfaction Pengguna $E$-Wallet

yang memiliki nilai terbesar yang dilihat dari nilai correlation antar error. Hasil uji kelayakan model yang telah di modifikasi dapat dilihat pada tabel 1 yang menunjukkan bahwa model sudah baik karena dari 5 indikator yang digunakan 4 diantaranya sudah menunjukkan baik meskipun 1 indikator marginal. Nilai dari masing-masing indikator yaitu GFI memiliki nilai 0,948, AGFI 0,900, TLI 0.975, RMSEA 0,033, dan NFI 0,919. Setelah dilakukan modifikasi, model yang sudah fit dapat dilihat pada gambar 1.

Tabel 1.

\section{UJI GOODNESS OF FIT INDICES DENGAN MODIFICATION}

\begin{tabular}{lccc}
\hline Goodness of Fit Indices & Batas & Hasil & Keterangan \\
\hline GFI & $>0,900$ & 0,948 & Baik \\
AGFI & $>0,900$ & 0,900 & Baik \\
TLI & $>0,900$ & 0,975 & Baik \\
RMSEA & $0,05-0,08$ & 0,033 & Marginal \\
NFI & $>0,900$ & 0,919 & Baik \\
\hline
\end{tabular}

Sumber: Output AMOS (Data diolah)

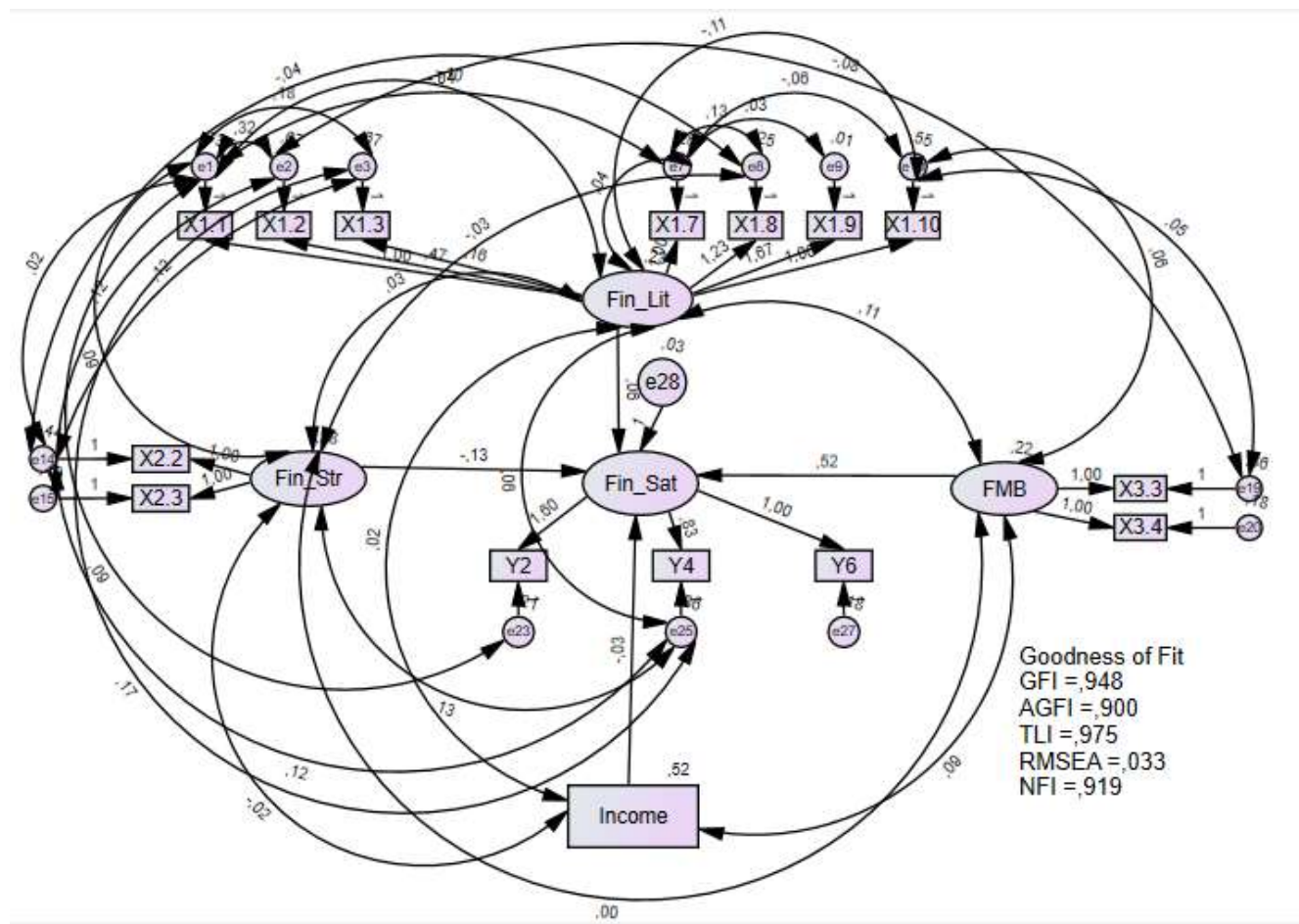

Sumber: Hasil pengolahan data dengan AMOS (Data diolah)

Gambar 1. MODEL AKHIR SEM

\section{Uji Hipotesis}

Tabel 2.

HASIL UJI HIPOTESIS

\begin{tabular}{llcccc}
\hline & Variabel & Estimate & S.E. & C.R. & P \\
\hline H1 & FL $\rightarrow$ FS & $-0,126$ & 0,077 & $-1,623$ & 0,105 \\
H2 & FSt $\rightarrow$ FS & 0,516 & 0,124 & 4,162 & 0,000 \\
H3 & FMB $\rightarrow$ FS & $-0,026$ & 0,041 & $-0,628$ & 0,530 \\
H4 & I $\rightarrow$ FS & 0,057 & 0,074 & 0,766 & 0,444 \\
\hline
\end{tabular}

Sumber: Output AMOS (Data diolah) 
Uji hipotesis dilakukan dengan melihat nilai signifikansi $\mathrm{P}$ dan nilai critical ratio. Nilai $\mathrm{P}$ digunakan untuk menunjukkan diterima atau tidaknya hipotesis, apabila mempunyai nilai $<0,05$ maka hipotesis diterima. Sedangkan nilai critical ratio digunakan untuk menentukan arah dari pengaruh variabel yang di uji. Pada tabel 2 menunjukkan bahwa nilai $\mathrm{P}$ pada $\mathrm{H} 1$ adalah 0,105 sehingga $\mathrm{H} 1$ ditolak, $\mathrm{H} 2$ diterima dengan nilai $\mathrm{P} 0,000, \mathrm{H} 3$ ditolak karena nilai $\mathrm{P}$ sebesar 0,530 , dan $\mathrm{H} 4$ ditolak dengan nilai $\mathrm{P}$ 0,444 .

\section{Pengaruh Financial Literacy terhadap Financial Satisfaction}

Berdasarkan hasil uji hipotesis, financial literacy tidak berpengaruh terhadap financial satisfation sehingga $\mathrm{H} 1$ ditolak. Hasil penelitian ini tidak sejalan dengan theory of planned behavior yang menyatakan bahwa faktor informasi dapat membantu seseorang dalam membuat keputusan keuangan yang baik sehingga kepuasan keuangan dapat tercapai (Ajzen, 2005:135). Setiap orang memiliki tingkatan literasi yang berbeda-beda, sehingga responden akan membuat keputusan yang berbeda berdasarkan informasi yang dimilikinya. Semakin berkembangnya zaman, seseorang dapat mudah dalam memperoleh informasi, namun informasi itu belum tentu adalah informasi yang baik, sehingga tindakan yang diambil belum tentu merupakan tindakan yang baik yang dapat berujung pada financial satisfaction. Upaya yang perlu dilakukan yaitu dengan menyeleksi terlebih dahulu terhadap informasi yang diterima untuk memastikan kebenaran informasi yang diperoleh. Adanya informasi yang baik akan meningkatkan tingkat literasi sehingga dapat membuat keputusan yang baik dan mencapai kepusan keuangan. Hasil respon dari responden menunjukkan tingkat literasi keuangan masyarakat Surabaya sebesar 54\% yang termasuk dalam kategori rendah. Hasil penelitian ini sejalan dengan penelitian yang dilakukan oleh Mukhafi (2020), Rusdini, D (2021), dan YAP et al. (2016) bahwa financial literacy tidak berpengaruh terhadap financial satisfaction.

\section{Pengaruh Financial Strain terhadap Financial Satisfaction}

Hasil uji hipotesis menunjukkan financial strain tidak memiliki pengaruh terhadap financial satisfaction sehingga $\mathrm{H} 2$ ditolak. Hal ini juga bertentangan dengan teori yang mendasarinya yaitu theory of planned behavior yaitu ketika seseorang tidak dapat mengambil tindakan dengan baik akan menimbulkan sebuah tekanan dalam dirinya (Ajzen, 2005:135). Tidak adanya pengaruh dalam penelitian ini dikarenakan responden tidak banyak mengalami tekanan keuangan sehingga mudah dalam mencapai financial satisfaction. Responden kebanyakan tidak memiliki hutang, dan pendapatan yang diterima sudah dikelola dengan baik untuk memenuhi kebutuhan dan keinginannya sehingga tidak merasakan tekanan keuangan. Kondisi psikologis setiap orang yang berbeda-beda juga menyebabkan financial strain tidak berpengaruh, kondisi kesulitan keuangan yang sedang dialami belum pasti dijadikan sebuah tekanan dalam dirinya. Kondisi kesulitan keuangan di anggap sebagai hal yang wajar sehingga tidak di anggap sebuah beban sehingga merasa tertekan, oleh karena itu kepuasan keuangan dapat dicapai dengan mudah. Selain itu mayoritas responden merupakan perempuan yang masih berstatus sebagai mahasiswa dan pelajar yang belum memiliki tanggungan, sehingga tidak merasakan sebuah tekanan keuangan. Hasil penelitian yang mendukung pernyataan bahwa financial strain tidak berpengaruh terhadap financial satisfaction adalah Sherlyani \& Pamungkas (2020).

\section{Pengaruh Financial Management Behavior terhadap Financial Satisfaction}

Berdasarkan uji hipotesis, financial management behavior terbukti berpengaruh secara signifikan terhadap financial behavior yang berarti $\mathrm{H} 3$ diterima. Hal tersebut sejalan dengan theory of planned behavior yaitu seseorang akan bertindak dengan baik untuk mencapai tujuan yang baik (Ajzen, 2005:135). Financial management behavior dan financial satisfaction mempunyai hubungan yang positif, dengan tingkat pengelolaan keuangan yang baik, maka seseorang akan merasakan kepuasan keuangan. Berdasarkan jawaban dari responden, dapat dilihat bahwa masyarakat Surabaya memiliki tingkat pengelolaan keuangan yang baik. Responden menunjukkan sikap pengelolaan keuangan yang baik dengan menghindari pembayaran tagihan di luar tanggal yang telah ditentukan sehingga tidak menimbulkan beban keuangan di masa depan. Pendapatan yang terima telah dikelola dengan baik untuk memenuhi kebutuhan sehari hari sesuai dengan anggaran yang telah ditentukan. Pengelolaan keuangan yang baik, maka keputusan keuangan yang diambil juga baik sehingga dapat mencapai 
financial satisfaction. Kepuasan keuangan dapat dirasakan ketika kebutuhan dalam hidup seseorang dapat terpenuhi akibat dari tindakan pengelolaan keuangan yang telah dilakukan. Hasil penelitian ini yang menyatakan bahwa financial management behavior berpengaruh terhadap financial satisfaction sejalan dengan penelitian yang dilakukan oleh Arifin (2018a), Arifin (2018b), Armilia \& Isbanah (2020), Darmawan \& Pamungkas (2019), Falahati et al. (2012), Halim \& Astuti (2015), Hasibuan et al. (2018), Mukhafi (2020), Prabowo \& Asandimitra (2021), Raprayogha et al. (2020), Saurabh \& Nandan (2018), Sawitri (2018), Wijaya \& Pamungkas (2020), Woodyard \& Robb (2016), dan YAP et al. (2016).

\section{Pengaruh Income terhadap Financial Satisfaction}

Berdasarkan uji hipotesis, income tidak berpengaruh terhadap financial satisfaction sehingga $\mathrm{H} 4$ ditolak. Berdasarkan teori subjective well-being seharusnya dengan income tinggi kebutuhan akan terpenuhi tercapai financial satisfaction, namun hasil dari penelitian ini tidak sejalan dengan teori tersebut (Diener et al., 2003). Income tidak memiliki pengaruh terhadap tingkat financial satisfaction karena income yang diterima berbanding lurus dengan beban yang ditanggung. Besarnya pendapatan yang diterima tidak dapat digunakan sebagai acuan bahwa seseorang dapat mencapai kepuasan keuangan. Mayoritas responden berusia 15-24 tahun yang masih memperoleh pendapatan dari orang tua sehingga keputusan keuangan belum dapat diambil secara mandiri karena masih bergantung kepada orang tua. Selain itu kepuasan keuangan tidak dapat dicapai dengan acuan pendapatan saja, pendapatan yang diperoleh tidak mampu memenuhi semua kebutuhan pribadi karena masih bergantung kepada orang tua sehingga harus menyesuaikan dengan kondisi masing-masing orang tua. Oleh karena itu kepuasan keuangan tidak dapat tercapai. Hasil penelitian ini sejalan dengan penelitian yang dilakukan oleh Rusdini et al. (2020) dan Rusdini, D (2021).

\section{KESIMPULAN}

Berdasarkan hasil pembahasan di atas dapat disimpulkan financial literacy tidak berpengaruh terhadap financial satisfaction karena adanya kemudahan infomasi yang bisa didapatkan namun informasi yang diterima belum tentu adalah informasi yang benar sehingga akan memengaruhi tingkat literasi keuangannya. Financial strain tidak berpengaruh terhadap financial satisfaction karena mayoritas responden merupakan perempuan yang masih berstatus mahasiswa dan pelajar yang belum memiliki tanggungan sehingga tidak merasakan financial strain. Financial management behavior berpengaruh terhadap financial satisfaction karena mayoritas responden telah mampu mengelola keuangan dengan baik dengan menggunakan pendapatan yang diperoleh sesuai dengan anggaran dan membayar beban secara tepat waktu sehingga kepuasan keuangan dapat tercapai. Income tidak berpengaruh terhadap financial satisfaction karena mayoritas pendapatan responden masih bergantung pada pendapatan yang diterima dari orang tua sehingga harus menyesuaikan dengan kondisi masingmasing orang tua, oleh karena itu income tidak dapat dijadikan tolok ukur tingkat financial satisfaction seseorang.

Otoritas Jasa Keuangan diharapkan dapat memberikan sosialisasi kepada masyarakat mengenai literasi keuangan yang benar agar informasi yang diterima benar-benar dapat meningkatkan literasi masyarakat. Bagi penyelenggara $e$-wallet, diharapkan dapat menambah informasi untuk membantu masyarakat dalam meningkatkan literasi keuangan dan fitur yang dapat membantu masyarakat dalam mengelola keuangannya sehingga dapat mencapai kepuasan keuangan. Bagi pengguna e-wallet, diharapkan dapat menyaring kembali informasi yang tersedia agar tingkat literasi keuangan dapat meningkat sehingga mampu mengelola keuangan dengan baik untuk mencapai kepuasan keuangan. Penelitian ini memiliki keterbatasan dalam hal variasi variabel independen, oleh karena itu bagi peneliti selanjutnya diharapkan dapat memodifikasi model yang berbeda dengan penelitian ini dengan menambahkan variabel seperti financial socialization, debt, risk tolerance, dan gaya hidup. Selain itu keterbatasan dalam penelitian ini adalah penyebaran kuesioner hanya dilakukan secara online sehingga pengambilan data kurang maksimal karena tidak dapat dilakukan secara mendalam dengan wawancara secara langsung dan penyebaran kuesioner juga tidak dapat dilakukan secara merata hanya tersebar di masyarakat yang berusia 15-24 tahun yang didominasi oleh mahasiswa dengan gender perempuan. 


\section{DAFTAR PUSTAKA}

Aboagye, Judith, and Ji Young Jung. (2018). Debt Holding, Financial Behavior, and Financial Satisfaction. Journal of Financial Counseling and Planning 29(2):208-18. doi: 10.1891/10523073.29.2.208.

Agung, Bintoro.(2020). Survei Ipsos Soroti Tingkat Kepuasan Pengguna terhadap Layanan Dompet Digital di E-Commerce. DailySocial. Retrieved November 4, 2020 (https://dailysocial.id/post/survei-ipsos-soroti-tingkat-kepuasan-pengguna-terhadap-layanandompet-digital-di-e-commerce).

Ajzen, Icek. (2005). Attides, Personallity and Behavior. Second Edi. New York: Open University Press.

Ali, Waqas., Saeed. Muhammad, Muhammad. Masood Khan, and Nasir. Ali Khan. (2020). "Financial Satisfaction of International Students in Malaysia." Sarhad Journal of Management Sciences (SJMS) 6(1):49-68.

Arifin, Agus Zainul. (2018a). Influence Factors toward Financial Satisfaction with Financial Behavior as Intervening Variable on Jakarta Area Workforce. European Research Studies Journal 21(1):90-103.

Arifin, Agus Zainul. (2018b). Influence of Financial Attitude, Financial Behavior, Financial Capability on Financial Satisfaction. 186(INSYMA):100-103.

Armilia, Nadhia, and Yuyun Isbanah. (2020). Faktor yang Memengaruhi Kepuasan Keuangan Pengguna Financial Technology di Surabaya. Jurnal Ilmu Manajemen 8(1):39-50.

Asebedo, Sarah D., and Melissa J. Wilmarth. (2017). Does How We Feel about Financial Strain Matter for Mental Health? Journal of Financial Therapy 8(1):63-78. doi: 10.4148/19449771.1130 .

Bagus, Kriswangsa. (2018). Jangan Salah! Ini Perbedaan E-Money dan E-Wallet dalam $\begin{array}{llll}\text { Mempermudah Transaksi. Retrieved } & 2020\end{array}$ (https://www.finansialku.com/perbedaan-e-money-dan-e-wallet/amp/\#).

bi.go.id. (2020). Statistik Sistem Pembayaran Bank Central Republik Indonesia. Retrieved October 1, 2020 (https://www.bi.go.id/id/statistik/ekonomi-keuangan/ssp/uang-elektronik-transaksi.aspx).

Candra, Jesslyn Winata, and Gesti Memarista. (2015). Faktor-Faktor yang Memengaruhi Financial Satisfaction pada Mahasiswa Universitas Kristen Petra. Finesta 3(2):1-6.

Chen, Haiyang, and Ronald. P. Volpe. (1998). An Analysis of Personal Financial Literacy Among College Students. Zhongguo Jiguang/Chinese Journal of Lasers 43(8):107-28. doi: 10.3788/CJL201643.0811001.

Darmawan, Deddy, and Ary Satria Pamungkas. (2019). Pengaruh Financial Attitude, Financial Behavior, dan Financial Knowledge terhadap Financial Satisfaction. JEMMA | Journal of Economic, Management and Accounting 2(2):9.

Diener, Ed, Shigehiro Oishi, and Richard E. Lucas. (2003). Personality, Culture, and Subjective WellBeing: Emotional and Cognitive Evaluations of Life. Annual Review of Psychology 54:403-25. doi: 10.1146/annurev.psych.54.101601.145056.

Dwinta, Ida dan Cinthia Yohana. (2010). Pengaruh Locus of Control, Financial Knowledge, Income 
May Amelia \& Yuyun Isbanah. Analisis Faktor-Faktor yang Memengaruhi Financial Satisfaction Pengguna $E$-Wallet

terhadap Financial Management Behavior. Jurnal Bisnis dan Akuntansi 12(3):131-44.

Falahati, Leila, Mohamad Fazli Sabri, and Laily H. J. Paim. (2012). Assessment a Model of Financial Satisfaction Predictors: Examining the Mediate Effect of Financial Behaviour and Financial Strain. World Applied Sciences Journal 20(2):190-97. doi: 10.5829/idosi.wasj.2012.20.02.1832.

Fauzia, Mutia. (2020). Dompet Digital Dana Jadi Penyalur Insentif Kartu Prakerja. Kompas.Com. $\begin{array}{lll}\text { Retrieved } \quad \text { October } & 14, & 2020\end{array}$ (https://amp.kompas.com/money/read/2020/10/14/141500226/dompet-digital-dana-jadipenyalur-insentif-kartu-prakerja).

Halim, Yopie Kurnia Erista, and Dewi Astuti. (2015). Financial Stressors, Financial Behavior, Risk Tolerance, Financial Solvency, Financial Knowledge, dan Kepuasan Finansial. Jurnal Finesta 3(1):19-23.

Hasibuan, Beby Kendida, Yeti Meliany Lubis, and Walad Altsani HR. (2018). Financial Literacy and Financial Behavior as a Measure of Financial Satisfaction. 46(EBIC):503-7. doi: 10.2991/ebic17.2018.79.

Joo, So-hyun, and John E. Grable. (2004). An Exploratory Framework of the Determinants of Financial Satisfaction. Journal of Business Ethics 51(1):31-39. doi: 10.1023/B.

Kholilah, Naila Al, and Rr. Iramani. (2013). Studi Financial Management Behavior pada Masyarakat Surabaya. Journal of Business and Banking 3(1):69. doi: 10.14414/jbb.v3i1.255.

Meilisa, Hilda. (2019). Penggunaan Mobile Payment Jatim Terbesar Ketiga di Pulau Jawa. Detiknews. Retrived November 03, 2020 (https://news.detik.com/berita-jawa-timur/d4825965/penggunaan-mobile-payment-jatim-terbesar-ketiga-di-pulau-jawa).

Mukhafi, Cicik Mahmudah. (2020). Faktor-Faktor yang Memengaruhi Financial Satisfaction Buruh di Kota Surabaya. Jurnal Ilmu Manajemen 8(4).

Nugraha, Dany Fajar, Indra Mulia Pratama, and Memen Kustiawan. (2020). Financial Satisfaction Increase: Effect of Income and Financial Literacy Factors (Study of MSMEs). 400(ICREAM):320-22. doi: 10.2991/assehr.k.200130.193.

Prabowo, Moch. Sigit, and Nadia Asandimitra. (2021). Faktor yang Memengaruhi Financial Satisfaction Pengguna E- Commerce di Surabaya. Jurnal Ilmu Manajemen 9(1).

Pusparisa, Yosepha. (2020). Mana yang Paling Favorit, E-Money atau E-Wallet? Katadata.Co.Id. Retrieved November 2, 2020 (https://katadata.co.id/muhammadridhoi/analisisdata/5f97c41b49705/mana-yang-paling-favorite-money-atau-e-wallet).

Raprayogha, Rusdi, Rika Dwi Ayu Parmitasari, and Rusnawati. (2020). Efek Mediasi Perilaku Keuangan dan Dampak Kepuasan Keuangan Masyarakat di Kota Makassar. Journal of Chemical Information and Modeling 10(1):62-82.

Rizkiawati, Nur Laili, and Nadia Asandimitra. (2018). Pengaruh Demografi, Financial Knowledge, Financial Attitude, Locus of Control dan Financial Self-Efficacy terhadap Financial Management Behavior Masyarakat Surabaya. Jurnal Ilmu Manajemen (JIM) 6(3):2.

Rusdini, D, A. (2021). Faktor yang Memengaruhi Financial Satisfaction pada Masyarakat Kabupaten Pamekasan. Jurnal Ilmu Manajemen 9(1). 
Rusdini, Dinda Arfiana, Tri Indah, Sri Mulyaningsih, Ishma Ghaisani, and Achmad Kautsar. (2020). Impact of Financial Knowledge, Socio-Demographics, and Debt on Financial Satisfaction of Kediri People Impact of Financial Knowledge, Socio-Demographics, and Debt on Financial Satisfaction of Kediri People. International Journal of Latest Engineering and Management Research (IJLEMR) 5(1):5.

Sahi, Shalini Kalra. (2013). Demographic and Socio-Economic Determinants of Financial Satisfaction: a Study of SEC-A Segment of Individual Investors in India. International Journal of Social Economics 40(2):127-50. doi: 10.1108/03068291311283607.

Saurabh, Kumar, and Tanuj Nandan. (2018). Role of Financial Risk Attitude and Financial Behavior as Mediators in Financial Satisfaction Empirical Evidence from India. South Asian Journal of Business Studies 7(2):207-24. doi: 10.1108/SAJBS-07-2017-0088.

Sawitri, Ni Nyoman. (2018). Behavior in Managing Revenue to Achieve Financial Satisfaction. Opcion 34(86):1274-91.

Sherlyani, Meitasari, and Satria Pamungkas. (2020). Pengaruh Financial Behavior, Risk Tolerance, dan Financial Strain terhadap Financial Satisfaction. Jurnal Manajerial dan Kewirausahaan II(1):272-81.

Wahab, Abdul, Ida Rahayu Aprilla, and Andi Mulia. (2019). Determinan Kepuasan Keuangan Pelaku Umkm. Assets: Jurnal Ekonomi, Manajemen dan Akuntansi 9(2):138. doi: 10.24252/assets.v9i2.13127.

Wijaya, Olivia. Sandra, and Ary. Satria Pamungkas. (2020). Pengaruh Financial Attitude, Financial Behavior, Financial Knowledge, dan Risk Tolerance terhadap Financial Satisfaction. Jurnal Manajerial dan Kewirausahaan II(3):631-42.

Woodyard, Ann Sanders, and Cliff A. Robb. (2016). Consideration of Financial Satisfaction: What Consumers Know, Feel and Do from a Financial Perspective. Journal of Financial Therapy 7(2). doi: 10.4148/1944-9771.1102.

YAP, Richard. Joshua. Christian, Farida Komalasari, and Hadiansah Ihsan. (2016). The Effect of Financial Literacy and Attitude on Financial Management Behavior and Satisfaction. Journal of Administrative Science \& Organization 23(3).

Yulinar, Bunga, * Yuliani, and Rasyid HS Umrie.(2020). Literasi Keuangan dan Kepuasan Keuangan dengan Gender sebagai Moderasi: Studi pada Mahasiswa di Kota Palembang. Jurnal Manajemen dan Bisnis Equilibrium 6(1):1-16. doi: 10.47329/jurnal_mbe.v6i1.424.

Zuhra, Wan Ulfa Nur. (2016). Gerakan Nasional Non Tunai. Retrieved December 26, 2020 (https://tirto.id/gerakan-nasional-non-tunai-9da). 